\title{
Clinical Efficacy of Intraoperative Cell Saver Autologous Blood Salvage in Emergency Thoracoscopic Surgery for Massive Hemothorax.
}

Hideki Itano ( $\square$ itano_h@yahoo.co.jp )

Daiyu-kai General Hospital https://orcid.org/0000-0001-6696-4281

\section{Takayuki Takeda}

Uji Tokushu-kai Hospital

\section{Hidehito Nakahara}

Kishiwada Tokushukai Byoin

\section{Toshinori Kobayashi}

Uji Tokushu-kai Hospital

Junsuke Hinami

Uji Tokushu-kai Hospital

\section{Research article}

Keywords: Massive hemothorax, Intraoperative autologous blood salvage, Cell Saver autotransfusion device, Blood transfusion, Thoracoscopic surgery

Posted Date: December 9th, 2020

DOI: https://doi.org/10.21203/rs.3.rs-122901/v1

License: (c) (i) This work is licensed under a Creative Commons Attribution 4.0 International License. Read Full License 


\section{Abstract}

Objectives: The objectives of this study were to investigate the efficacy of intraoperative Cell Saver autologous blood salvage in emergency thoracoscopic surgery for massive hemothorax.

methods: Nine consecutive cases, including 8 idiopathic hemopneumothoraxes and 1 late-onset traumatic hemothorax, for which emergency surgery was performed at Uji Tokushu-kai Hospital between 2009 and 2016, were retrospectively reviewed.

Results: The median total blood loss was 2200 cc (range, 840-4170 cc). Intraoperative Cell Saver autotransfusion with a median volume of $820 \mathrm{cc}$ was performed in the last 7 patients. The first 2 patients who did not receive an autotransfusion required substantially more allogeneic blood transfusion (10 and $14 \mathrm{U}$, respectively), while the other 7 autotransfusion patients required much smaller amounts of allogeneic transfusion (4 $\mathrm{U}$ in 3 and $0 \mathrm{U}$ in 4). Four autotransfusion patients who did not undergo preoperative chest tube drainage and/or who had drainage of $<150 \mathrm{cc}$ received a greater amount of intraoperative autotransfusion (mean, $1162 \pm 414 \mathrm{cc}$ ) than the other 3 patients who had a chest tube drainage of $\geq 150$ cc (mean, $666.7 \pm 150 \mathrm{cc} ; \mathrm{P}=0.0574)$. Torn and bleeding arteries were thoracoscopically clipped in 7 patients. One patient with right lung collapse over 2.5 days developed severe acute respiratory distress syndrome intraoperatively, but fully recovered.

Conclusions: Utilizing intraoperative autologous blood salvage with the sparing of preoperative chest tube drainage to the maximum possible extent is an efficient strategy to reduce both overall blood loss and allogeneic blood transfusion in emergency thoracoscopic surgery for massive hemothorax.

\section{Introduction}

Massive hemothorax is one of the most common thoracic emergencies in clinical practice. Patients with massive hemothorax may deteriorate quickly with hemodynamic instability resulting from progressive blood loss into the pleural cavity. Urgent chest tube drainage is usually performed especially when tension thorax is suspected. If the patient has persistent hemodynamic instability and suspected continuous bleeding, emergency surgical intervention and immediate blood transfusions are required. In such patients, blood transfusions by intraoperative autologous blood salvage (IABS) could limit the overall blood loss and reduce the need for allogeneic transfusion, which is associated with known morbidities and mortalities. In the present study, we retrospectively evaluated a series of consecutive patients who presented with massive hemothorax and were treated with emergency thoracoscopic surgery, with a focus on the use of the Cell Saver IABS and the reduction of allogeneic blood transfusion.

\section{Materials And Methods}

The cases were comprised of 8 idiopathic hemopneumothoraxes and 1 late-onset traumatic hemothorax. All the patients had a total blood loss of $\geq 800 \mathrm{cc}$ (mean, $2524 \pm 1232 \mathrm{cc}$; range, $840-4170 \mathrm{cc}$ ) and underwent emergency complete thoracoscopic surgery in which the surgeon's vision was only through 
video monitoring at Uji Tokushu-kai Hospital between 2009 and 2016. In the last 7 cases, the Cell Saver autotransfusion device (Cell Saver 5+; Haemonetics Japan, Tokyo, Japan), a red blood cell recovery system, was used intraoperatively for blood transfusion.

\section{Statistical Analyses}

Data were collected and analyzed using theGraphPad Prizm version 5.04 software (GraphPad Software, Inc., San Diego, CA, USA) by means of an unpaired $t$-test with Welch's correction. All data are expressed as mean \pm standard deviation. Statistical significance was set at $P<0.05$.

\section{Results}

The presented cases consisted of 8 men and 1 woman, with a mean age of $35 \pm 13$ years. Five of the 9 patients were active smokers. Hemothorax was on the right and left sides in 3 and 6 patients, respectively. Seven patients (78\%) showed signs of hypovolemic shock in the form of tachycardia and/or hypotension upon admission (Table 1). The chest radiographs taken on the initial hospital visits showed a significant mediastinal shift in all the patients, except for Patient 6 , who had the lowest total blood loss (840 cc; Table 1). Except for Patient 6, all the other patients were transferred to our institution after their initial visit to another hospital. In 5 of the 8 patients, chest tube drainage was performed at the initial visit. Patients 5 , 6 , and 8 did not have preoperative chest tube placement. In Patients 2, 3, 4, and 9, who had chest tube drainage, tubes were clamped after blood volume ranging from 100 to $1900 \mathrm{cc}$ had been drained. Patient 1 had an ineffective chest tube with no drainage since placement. Patient 7 underwent chest tube drainage twice; initial chest tube was occluded by clot after $600 \mathrm{cc}$ of blood was drained, and the second chest tube was placed upon arrival at our hospital with a subsequent drainage of $1400 \mathrm{cc}$ prior to clamping. The mean total preoperative chest tube drainage in Patients 2, 3, 4, 7, and 9 was $1190 \pm 825 \mathrm{cc}$ (range, 100$2000 \mathrm{cc}$ ). Except for Patients 1 and 2, all the other patients underwent IABS using the Cell Saver $5+$ autotransfusion device, with a mean autologous blood volume of $950 \pm 404 \mathrm{cc}$ (range, 520-1700 cc). Patients 1 and 2, who did not undergo IABS, required substantially more allogeneic blood transfusion (10 and $14 \mathrm{U}$, respectively), while the other 7 IABS patients required far smaller amounts of allogeneic transfusion ( $4 \mathrm{U}$ in 3 and $0 \mathrm{U}$ in 4 patients). Among the 7 IABS patients, 3 who did not undergo preoperative chest tube drainage (Patients 5,6 , and 8 ) and/or one who had a chest tube drainage of $<150 \mathrm{cc}$ (Patient 3 ) tended to receive greater amount of IABS transfusion (mean, $1162 \pm 414 \mathrm{cc}$; range, $720-1700 \mathrm{cc}$ ) than the 3 patients who had a preoperative chest tube drainage of $\geq 150 \mathrm{cc}$ (Patients 4,7 , and 9) with a mean IABS transfusion volume of $666.7 \pm 150 \mathrm{cc}$ (range, $520-820 \mathrm{cc}$; $P=0.0574$; Fig. 1). By contrast, in 3 IABS patients (Patients 3, 5, and 8), who received autologous transfusions of $\geq 1000 \mathrm{cc}$, the amount of preoperative chest tube drainage (mean, $33.3 \pm 57.7 \mathrm{cc}$; range, $0-100 \mathrm{cc}$ ) showed a decreasing trend, as compared with that in the other 4 IABS patients (Patient 4, 6, 7, and 9; mean, $1125 \pm 984 \mathrm{cc}$, range 0$2000 \mathrm{cc})$ who had autotransfusions of $<1000 \mathrm{cc}(\mathrm{P}=0.0569$, Table 2$)$. 
Table 1

Patient characteristics

\begin{tabular}{|lllllll|}
\hline Patient & $\begin{array}{l}\text { Age } \\
\text { (years) }\end{array}$ & Sex & Side & Etiology & $\begin{array}{l}\text { Hemodynamic } \\
\text { instability } \\
\text { on admission }\end{array}$ & $\begin{array}{l}\text { Mediastinal shift } \\
\text { on chest } \\
\text { radiographs }\end{array}$ \\
\hline 1 & 42 & M & L & SHP & + & + \\
\hline 2 & 39 & M & L & SHP & + & + \\
\hline 3 & 22 & M & R & SHP & + & + \\
\hline 4 & 26 & M & R & SHP & - & + \\
\hline 5 & 16 & M & R & SHP & + & + \\
\hline 6 & 38 & F & L & SHP & - & + \\
\hline 7 & 37 & M & L & SHP & + & + \\
\hline 8 & 61 & M & L & traumatic & + & + \\
\hline 9 & 30 & M & L & SHP & + & + \\
\hline M: male, F: female, L: left, R: right, SHP: spontaneous hemopneumothorax
\end{tabular}


Table 2

The amount of blood loss and transfusion

\begin{tabular}{|c|c|c|c|c|c|c|c|}
\hline Patient & $\begin{array}{l}\text { Preoperative } \\
\text { chest tube } \\
\text { placement }\end{array}$ & $\begin{array}{l}\text { Preoperative } \\
\text { chest tube } \\
\text { drainage } \\
\text { (A) }\end{array}$ & $\begin{array}{l}\text { Intrathoracic } \\
\text { blood } \\
\text { at surgery } \\
\text { (B) }\end{array}$ & $\begin{array}{l}\text { Total } \\
\text { blood } \\
\text { loss } \\
\text { (A)+ } \\
\text { (B) }\end{array}$ & $\begin{array}{l}\text { Cell } \\
\text { Saver } \\
\text { IABS }\end{array}$ & $\begin{array}{l}\text { Autologous } \\
\text { transfusion }\end{array}$ & $\begin{array}{l}\text { Allogeneic } \\
\text { transfusion }\end{array}$ \\
\hline & & (cc) & (cc) & (cc) & & (cc) & (U) \\
\hline 1 & + & none & 2200 & 2200 & - & 0 & 10 \\
\hline 2 & + & 1350 & 2820 & 4170 & - & 0 & 14 \\
\hline 3 & + & 100 & 2030 & 2130 & + & 1227 & 4 \\
\hline 4 & + & 600 & 700 & 1300 & + & 660 & 4 \\
\hline 5 & - & none & 1530 & 1530 & + & 1000 & 0 \\
\hline 6 & - & none & 840 & 840 & + & 720 & 0 \\
\hline 7 & + & 2000 & 1630 & 3630 & + & 820 & 0 \\
\hline 8 & - & none & 4120 & 4120 & + & 1700 & 4 \\
\hline 9 & + & 1900 & 900 & 2800 & + & 520 & 0 \\
\hline
\end{tabular}

The time between the onset of hemothorax and surgery (onset-to-surgery time) was variable (range, 6.660 hours) with a mean of $21.8 \pm 17$ hours. Three patients (Patients 2, 7, and 9) underwent surgery within 10 hours; 2 (Patients 1 and 8 ) within 20 hours; 3 (Patients 4, 5, and 6) between 20 and 40 hours; and 1 (Patient 3), at 60 hours after the onset of hemothorax (Table 3). 
Table 3

Correlation between time course and blood loss

\begin{tabular}{|llllll|}
\hline Patient & $\begin{array}{l}\text { Total blood } \\
\text { loss } \\
(\text { A) }\end{array}$ & $\begin{array}{l}\text { Onset-to- } \\
\text { surgery } \\
\text { time } \\
(\text { B })\end{array}$ & $\begin{array}{l}\text { Temporal } \\
\text { admission } \\
\text { to the first } \\
\text { hospital }\end{array}$ & $\begin{array}{l}\text { Mean } \\
\text { bleeding } \\
\text { rate } \\
\text { (A)/(B) }\end{array}$ & $\begin{array}{l}\text { Transfer-to-surgery } \\
\text { time }\end{array}$ \\
\hline & (cc) & (hours) & & (cc/hour) & (hours) \\
\hline 1 & 2200 & 16 & + & 138 & 2 \\
\hline 2 & 4170 & 9 & - & 463 & 1 \\
\hline 3 & 2130 & 60 & - & 36 & 1.7 \\
\hline 4 & 1300 & 28 & + & 46 & 2 \\
\hline 5 & 1530 & 27 & + & 57 & 1.7 \\
\hline 6 & 840 & 35 & - & 24 & 2.3 \\
\hline 7 & 3630 & 8.5 & - & 427 & 3.2 \\
\hline 8 & 4120 & 18 & - & 229 & 12 \\
\hline 9 & 2800 & 6.6 & - & 424 & 1.5 \\
\hline
\end{tabular}

The mean bleeding rate, that is, the total blood loss per hour (onset-to-surgery time), which represents the mean speed of bleeding, was widely variable (range, 24-463 cc/hour). Three patients who had a mean bleeding rate of $\geq 400 \mathrm{cc} /$ hour (Patients 2,7 , and 9) simultaneously had an onset-to-surgery time of $<10$ hours and further had a larger amount of total blood loss exceeding $2800 \mathrm{cc}$. These 3 patients had significantly higher mean bleeding rate (mean, $438 \pm 21.7 \mathrm{cc} /$ hour; range, $424.0-463.0 \mathrm{cc} /$ hour; $\mathrm{P}=0.006$ ), significantly shorter onset-to-surgery times (mean, $8.03 \pm 1.27$ hours; range, 6.6-9.0 hours; $P=0.0091$; Fig. 2), and significantly larger total blood loss volumes (mean, $3533 \pm 690 \mathrm{cc}$; range, $2800-4170 \mathrm{cc} ; \mathrm{P}=$ 0.0246; Fig. 3), than the other 6 patients.

All the patients underwent emergency thoracoscopic surgery within 3 hours of arriving at our institution (mean, $1.92 \pm 0.64$ hours), except for Patient 8 , who had a traumatic hemothorax and underwent thoracoscopic surgery 12 hours after arriving (Table 3 ).

In 7 patients (78\%), torn, bleeding arteries were identified and clipped in a complete thoracoscopic surgery (Online Resource 1). In the first 5 cases (Patients 1-5), mini-thoracotomies $\geq 3.0 \mathrm{~cm}$ in length were made, whereas in the last 4 cases, only ports with a length of $<2.0 \mathrm{~cm}$ were made to enter the thorax without a mini-thoracotomy. The incision size required for surgery has since become even smaller (Table 4). In 5 of the patients who had a higher amount of blood loss and transfusion, 2 chest tubes were effectively placed at the end of the surgery in the apex and base for prophylaxis against postoperative lung atelectasis with a basal accumulation of effusion (Table 4). 
Table 4

Findings from the thoracoscopic surgery and hospital stay

\begin{tabular}{|llllll|}
\hline Patient & $\begin{array}{l}\text { Mini- } \\
\text { thoracotomy } \\
\text { size }(\mathbf{c m})\end{array}$ & $\begin{array}{l}\text { Port size } \\
(\mathbf{m m})\end{array}$ & $\begin{array}{l}\text { Clipping of } \\
\text { torn artery }\end{array}$ & Chest tubes & $\begin{array}{l}\text { Hospital } \\
\text { discharge } \\
\text { (POD) }\end{array}$ \\
\hline 1 & 7 & 10 & apex $\times 1$ & apex & 16 \\
\hline 2 & 5 & 10,5 & apex $\times 1$ & apex, base & 14 \\
\hline 3 & 4 & 10,5 & NI & apex, base & 12 \\
\hline 4 & 3 & 10,5 & apex $\times 1$ & apex, base & 9 \\
\hline 5 & 3 & 5 & apex $\times 1$ & apex & 7 \\
\hline 6 & none & $20,5,5$ & apex $\times 1$ & apex & 8 \\
\hline 7 & none & $15,15,5$ & apex $\times 1$ & apex, base & 9 \\
\hline 8 & none & 20,5 & NI & apex, base & 11 \\
\hline 9 & none & $15,5,5$ & apex $\times 1$ & apex & 8 \\
\hline Nl: torn arteries not identified, POD: postoperative day & \\
\hline
\end{tabular}

Perioperative complications were encountered in some patients. Lung atelectasis accompanied with basal accumulation of effusion was found in Patient 1 but was resolved by placing another chest tube in the base. Patient 3 , who had a complete right lung collapse over 2.5 days, and a large amount of total blood loss (2130 cc) experienced severe acute respiratory distress syndrome (ARDS), which started intraoperatively. However, the patient fully recovered following intensive care, including 3 days of mechanical ventilation, administration of methyl prednisolone, vigorous diuresis, and bronchoscopic toileting, and was subsequently discharged on postoperative day 12 .

\section{Discussion}

Few studies have been reported on the usefulness of IABS in emergency surgery for massive hemothorax [1-3]. Although massive hemothorax with significant blood loss and hemodynamic instability ordinarily requires urgent intervention, including emergency surgery and allogeneic blood transfusions, an innovative IABS technique can reduce the overall blood loss and thereby avoid the need for allogeneic transfusion, which is associated with known adverse clinical outcomes and life-threatening complications. IABS can also save time for the preparation of allogeneic blood. IABS was introduced in the early 1980s and rapidly gained clinical acceptance as a safe alternative to allogeneic transfusion. IABS is now commonly used during surgeries with the potential for massive bleeding, such as cardiac surgery, vascular surgery, spinal surgery, or liver transplant [4, 5]. IABS systems, including Haemonetics Cell Saver 5+, which was used in this study, entail the collection and reinfusion of a patient's own blood that is lost throughout surgery. First, it collects shed blood from the operative field into a centrifuge. Heparin anticoagulant is added, and the 
contents are filtered to remove platelets, white blood cells (WBCs), free hemoglobin, and concomitants such as clots and lipids from the operating field. RBCs are then washed with saline, separated by differential centrifugation, and reinfused. The final blood consists of washed, concentrated RBCs with a hematocrit count of approximately $53.7-60 \%$ suspended in normal saline solution. The blood processing speed is 3-5 min. IABS systems have been reported to bring about significant attenuation of the inflammatory response in processed blood, demonstrating the effective elimination of several inflammatory cytokines (TNF-a, IL-2, IL-6, IL-8, etc.), WBCs, and markers of leukocyte activation (myeloperoxidase and elastase) [6, 7]. On the other hand, RBCs salvaged from the operating field in IABS have been suggested to result in bleeding due to dilutional coagulopathy caused by the elimination of platelets and coagulation factors [1,2]. Recent evidence has, however, demonstrated that no significant coagulopathy is associated with IABS [8]. IABS also carries the risk of bacterial contamination from the operating fields, but none of the patients in our study developed an infection.

Adverse clinical outcomes among recipients of allogeneic blood transfusion have been widely reported, such as higher rates of serious perioperative infections, post-injury multiple-organ failure, pulmonary, renal, and cardiac complications, and higher mortality rate [9]. "Blood storage lesions" and subsequent immune suppression are likely important contributors to these morbidities. Older allogeneic blood is known to increase morbidity and mortality as compared with newer blood [10]. Refrigerated storage of blood results in a "storage lesion," characterized by rheological changes, metabolic derangements, changes in oxygen affinity and delivery, oxidative injury to lipids and proteins, RBC shape change, loss of membrane carbohydrate, and reduced RBC lifespan. These changes become more pronounced with longer storage, promoting in vivo hemolysis $[11,12]$. Other known serious adverse events associated with allogeneic blood transfusion include incompatibility reactions and transfusion-transmitted diseases. Furthermore, many countries often face a shortage of allogeneic blood and issues of increasing cost [13]. Another lifethreatening complication of allogeneic transfusion includes transfusion-related acute lung injury (TRALI), which was reported in approximately $2.4 \%$ of cardiac surgery patients with $13 \%$ mortality in a Dutchnested, case-control cohort study [14]. TRALI is the acute onset of non-cardiogenic pulmonary edema that occurs within 6 hours of transfusion and is the leading cause of transfusion death. TRALI is thought to be a two-event entity. The first event is the presence of an inflammatory condition in the host that causes endothelial activation, which leads to neutrophil sequestration and priming in the lung. The second event is transfusion of an allogeneic blood product containing either donor leukocyte antibody or bioactive lipids (lysophosphatidylcholines) that accumulate during storage of RBCs or platelets, providing additional signals for neutrophil activation, resulting in the clinical syndrome of pulmonary edema. The onset of TRALI correlates with the total volume of RBC products stored for $\geq 14$ days $[15,16]$. In the present study, Patient 3 , who had $4 \mathrm{U}$ of allogeneic and $1227 \mathrm{cc}$ of IABS transfusions, experienced severe ARDS. While severe ARDS was accompanied by massive, watery intra-airway secretion that started intraoperatively in this case, how much this ARDS is attributable to TRALI by allogeneic blood transfusion rather than by reexpansion lung edema following prolonged lung atelectasis ( $\geq 2.5$ days) or a massive fluid infusion to compensate for hemodynamic instability caused by large blood loss $(2130 \mathrm{cc})$ is unclear. Generally, patients with massive hemothorax, who have undergone a large volume overload with both fluid and blood, and especially with a more prolonged period of lung collapse, seem highly vulnerable to re- 
expansion lung edema. Tension thorax, which is prone to accompany hemopneumothorax rather than simple hemothorax, may partially contributed to re-expansion edema.

Owing to such adverse clinical outcomes and life-threatening complications, allogeneic blood transfusion should be avoided as much as possible. From this standpoint, IABS is an effective blood conservation strategy in surgeries with massive bleeding.

Strong clinical and economic evidence supports the use of IABS in surgeries with massive bleeding, as IABS results in a significant reduction in allogeneic RBC and coagulant product transfusions [4], earlier discharge from the intensive care unit, and a lower incidence of myocardial infarction in cardiac $[5,8]$ and pediatric cardiac surgery patients [17]. On the other hand, IABS is believed to be cost-effective only when large blood loss equivalent to1-2 units of RBCs can be salvaged during surgery [13]. While a minimum of 600-800 $\mathrm{ml}$ of intraoperative bloodshed is required for the Cell Saver devices to process, only one-third of this amount is returned. In cases where the system is set up and fails to collect enough volume to process, a considerable cost is incurred for zero benefit [18].

As the blood drained through the chest tube cannot be processed for reinfusion because of its considerable risk of contamination, the greater the preoperative chest tube drainage of intrathoracic shed blood, the less the amount of blood available for IABS, thereby increasing the likelihood of a subsequent allogeneic transfusion in surgery for massive hemothorax. Among the 7 IABS patients in the present study, 3 who did not undergo preoperative chest tube drainage (patients 5, 6, and 8 ) and/or one who had a chest tube drainage of $<150 \mathrm{cc}$ (Patient 3 ) showed a trend toward receiving more IABS transfusions (mean, $1162 \pm 414 \mathrm{cc}$ ), than the 3 patients who had preoperative chest tube drainage of $\geq 150 \mathrm{cc}$ (patients 4,7 , and 9; mean, $666.7 \pm 150 \mathrm{cc} ; \mathrm{P}=0.0574)$; that is, the amount of IABS transfusion was inversely proportional to the amount of preoperative chest tube drainage and allogeneic transfusion, which means that the lower the amount of chest tube drainage, the larger the amount of IABS autotransfusion, and the fewer units of allogeneic transfusion were required irrespective of the total amount of shed blood. Thus, from the standpoint of promoting maximal IABS utilization and limiting allogeneic blood transfusion, preoperative chest tube drainage should be spared to the maximum possible extent as long as hemodynamics remain stable.

Hemodynamic status at the first hospital visit varied in each patient; some patients who had continuous or vigorous bleeding from the onset of hemothorax might appear with relatively unstable conditions, whereas others who had substantial initial bleeding with the subsequent hemostasis caused by the spasm of torn arteries, or by compression of the intrathoracic clot might show more stable hemodynamic conditions. In the present study, 3 patients who had an onset-to-surgery time of $<10$ hours (patient 2, 7, and 9) simultaneously had a mean bleeding rate of $\geq 400 \mathrm{cc} /$ hour and further had a larger total blood loss exceeding $2800 \mathrm{cc}$. These three patient had a significantly higher mean bleeding rate (mean, $438 \pm$ $21.7 \mathrm{cc} /$ hour, range, $424.0-463.0 \mathrm{cc} /$ hour; $\mathrm{P}=0.006$; Fig. 2), significantly greater total blood loss (mean, $3533 \pm 690 \mathrm{cc}$; range, $2800-4170 \mathrm{cc} ; \mathrm{P}=0.0246 ; \mathrm{Fig}$. 3), and further significantly shorter onset-to-surgery time (mean, $8.03 \pm 1.27$ hours; range, $6.6-9.0$ hours; $P=0.0091$ ), than the other 6 patients. These results suggest that more vigorous arterial bleeding probably started concurrently with the onset and continued 
until surgery in these 3 patients. This high mean bleeding rate (mean, $438 \pm 21.7 \mathrm{cc} /$ hour, range, $424.0-$ $463.0 \mathrm{cc}$ /hour) could have led to hemodynamic instability sooner, promoting surgical intervention at an earlier timing (Online Resource 1).

As for surgical approaches, all patients in this study were treated with complete thoracoscopic surgery, which is less invasive and can provide far superior vision as compared with thoracotomy alone. It is wellsuited for observing the entire pleural cavity following evacuation of shed blood and clot, and for searching and clipping the bleeding torn arteries. The thoracoscopic procedures have been refined over the years, and the incision sizes have decreased. This is partially because it has turned out that the evacuation of massive blood and coagula is feasible even through smaller-sized ports in most cases.

In the present study, the chest radiographs taken at the initial visit to the hospital demonstrated a significant mediastinal shift in all the patients except for Patient 6 , who had the lowest net blood loss. Once tension thorax with some hemodynamic instability is demonstrated in patients with hemothorax or hemopneumothorax, immediate chest tube placement is usually required. All the patients in this study except for Patient 8 had spontaneous hemopneumothorax that tended to accompany tension thorax more easily than simple hemothorax, with chest tube placement required more frequently. In these cases, the best practice might be to place the chest tube first and then clamp it when the hemodynamics is stabilized with the relief of the mediastinal shift by the evacuation of air and blood. This can minimize unnecessary blood loss and allow for scheduling of early emergency surgery. On the basis of the results of this study, we propose the following algorithm for treating hemothorax with hemodynamic instability: 1) stabilization of hemodynamics on arrival by fluid infusion, 2) radiological diagnosis (chest radiography and/or computed tomography scan), 3) chest tube placement for the relief of tension thorax as required, 4) preparation of allogeneic blood as needed, and 5) scheduling early emergency thoracoscopic surgery in combination with IABS when $\geq 800 \mathrm{cc}$ of intrathoracic blood is suspected.

In conclusion, utilizing the Cell Saver IABS with the sparing of preoperative chest tube drainage to the maximum possible extent is an efficient strategy to reduce both overall blood loss and subsequent allogeneic blood transfusion in emergency thoracoscopic surgery for massive hemothorax.

\section{Declarations}

\section{Ethics approval and consent to participate}

The present study was ethically approved by Institutional Review Boards in Uji Tokushu-kai Hospital (\#2016-10-邓). Informed consent was obtained from all patients.

\section{Consent for publication}

Informed consent for publication was obtained from the patients. 


\section{Competing interests}

The authors have no relevant competing interests.

\section{Funding}

The authors have no relevant funding.

\section{Authors' contribution}

$\mathrm{HI}$ designed the study, performed surgery, and analyzed the data. TT participated in the care of the patients. HN, TK and JH participated in surgery, the care of the patients, and the data collection.

\section{Acknowledgments}

The authors appreciate all medical staff who contributed to the care of the patients in this study. The authors also appreciate Editage (www.editage.com) for English language editing.

\section{References}

1. Sakamoto K, Ohmori T, Takei H, Hasuo K, Rino Y, Takanashi Y. Autologous salvaged blood transfusion in spontaneous hemopneumothorax. Ann Thorac Surg. 2004;78:705-7.

2. Kamiyoshihara M, Ibe T, Takeyoshi I. The utility of an autologous blood salvage system in emergency thoracotomy for a hemothorax after chest trauma. Gen Thorac Cardiovasc Surg. 2008;56:222-5.

3. Ma HS, Ma JH, Xue FL, Fu XN, Zhang N. Clinical analysis of thoracoscopic surgery combined with intraoperative autologous blood transfusion in the treatment of traumatic hemothorax. Chin $\mathrm{J}$ Traumatol. 2016;19:371-2.

4. Carless PA, Henry DA, Moxey AJ, O'Connell D, Brown T. Fergusson DA.ã⿰口口Cell salvage for minimising perioperative allogeneic blood transfusion. Cochrane Database Syst Rev. 2010;4:CD001888.

5. Wang G, Bainbridge $D$, Martin J, Cheng $D$. The efficacy of an intraoperative cell saver during cardiac surgery: A meta-analysis of randomized trials. Anesth Analg. 2009;109:320-30.

6. Amand T, Pincemail J, Blaffart F, Larbuisson R, Limet R, Defraigne JO. Levels of inflammatory markers in the blood processed by autotransfusion devices during cardiac surgery associated with cardiopulmonary bypass circuit. Perfusion. 2002;17:117-23.

7. Naumenko KS, Kim SF, Cherkanova MS, Naumenko SE. The Haemonetics® Cell Saver 5 washing properties: effect of different washing pump and centrifuge speeds. Interact Cardiovasc Thorac Surg. 2008;7:759-63.

8. Vonk AB, Meesters MI, Garnier RP, Romijn JW, van Barneveld LJ, Heymans MW, et al. Intraoperative cell salvage is associated with reduced postoperative blood loss and transfusion requirements in cardiac 
surgery: a cohort study. Transfusion. 2013;53:2782-9.

9. Ferraris VA, Davenport DL, Saha SP, Austin PC, Zwischenberger JB. Surgical outcomes and transfusion of minimal amounts of blood in the operating room. Arch Surg. 2012;147:49-55.

10. Koch CG, Li L, Sessler DI, Figueroa P, Hoeltge GA, Mihaljevic T, et al. Duration of red-cell storage and complications after cardiac surgery. N Engl J Med. 2008;358:1229-39.

11. Solomon SB, Wang D, Sun J, Kanias T, Feng J, Helms CC, et al. Mortality increases after massive exchange transfusion with older stored blood in canines with experimental pneumonia.ã⿰B口lood 2013;121:1663-72.

12. Klein HG. The red cell storage lesion(s): of dogs and men. Blood Transfus. 2017;15:107-11.

13. Davies L, Brown TJ, Haynes S, Payne K, Elliott RA, McCollum C. Cost-effectiveness of cell salvage and alternative methods of minimizing perioperative allogeneic blood transfusion: a systematic review and economic model. Health Technol Assess. 2006;10:iii-v. ix-x,1-210.

14. Vlaar AP, Hofstra JJ, Determann RM, Veelo DP, Paulus F, Kulik W, et al. The incidence, risk factors, and outcome of transfusion-related acute lung injury in a cohort of cardiac surgery patients: a prospective nested case-control study. Blood. 2011;117:4218-25.

15. Kelher MR, Masuno T, Moore EE, Damle S, Meng X, Song Y, et al. Plasma from stored packed red blood cells and MHC class I antibodies causes acute lung injury in a 2-event in vivo rat model. Blood. 2009;113:2079-87.

16. Otrock ZK, Liu C, Grossman BJ. Transfusion-related acute lung injury risk mitigation: an update. Vox Sang. 2017;112:694-703.

17. Cholette JM, Powers KS, Alfieris GM, Angona R, Henrichs KF, Masel D, et al. Transfusion of cell saver salvaged blood in neonates and infants undergoing open heart surgery significantly reduces RBC and coagulant product transfusions and donor exposures: results of a prospective, randomized, clinical trial. Pediatr Crit Care Med. 2013;14:137-47.

18. Attaran S, Mcllroy D, Fabri BM, Pullan MD. The use of cell salvage in routine cardiac surgery is ineffective and not cost-effective and should be reserved for selected cases. Interact Cardiovasc Thorac Surg. 2011;12:824-6.

\section{Figures}




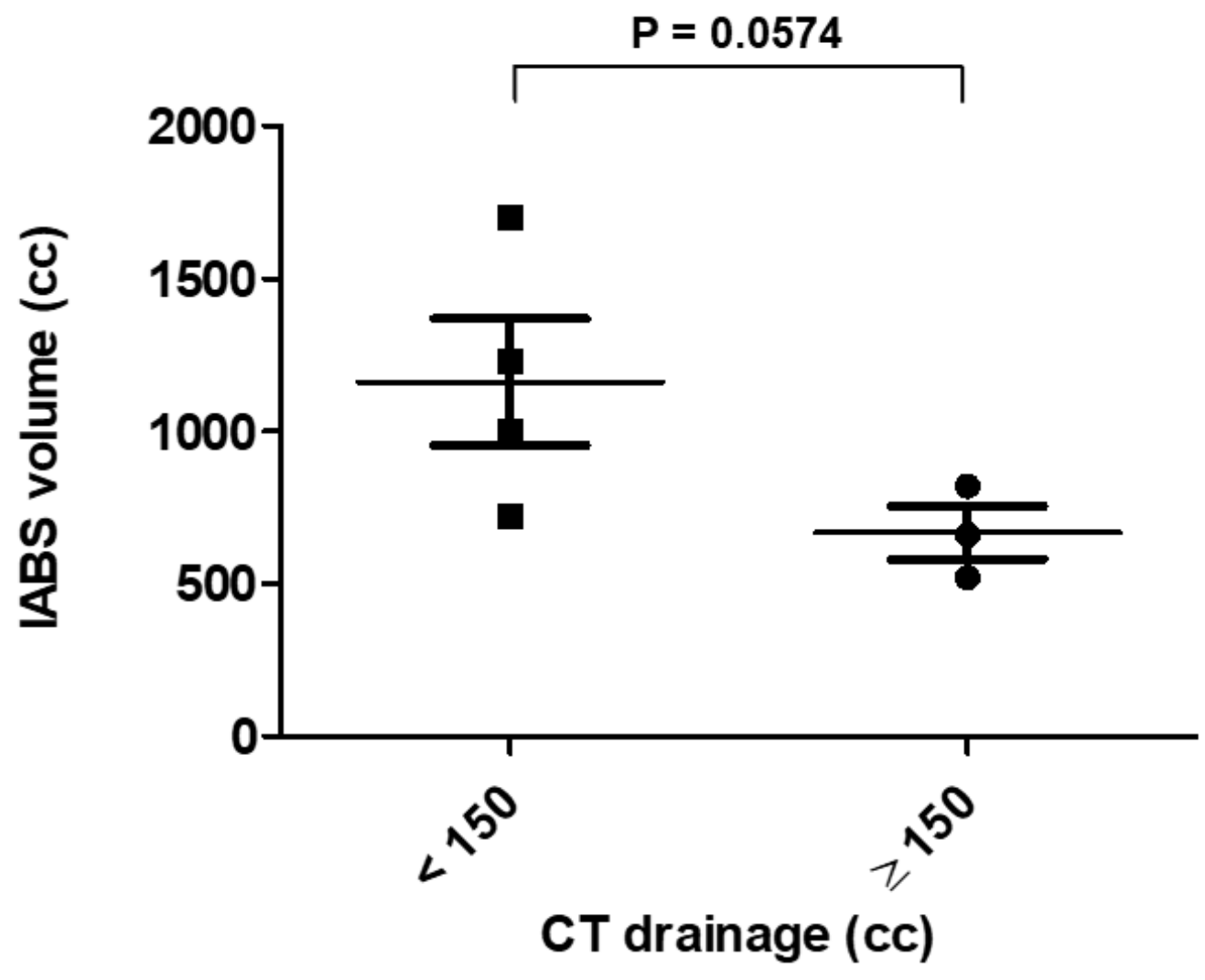

Figure 1

Among the 7 IABS patients, 3 who did not undergo preoperative CT drainage (Patient 5, 6, and 8) and/or one who had a CT drainage of $<150 \mathrm{cc}$ (Patient 3 ) tended to receive greater amounts of IABS transfusion (mean, $1162 \pm 414 \mathrm{cc}$ ), than the 3 patients who had preoperative CT drainage of $\geq 150 \mathrm{cc}$ (Patient 4, 7, and 9) with a mean IABS transfusion of $666.7 \pm 150 \mathrm{cc}(P=0.0574)$. 

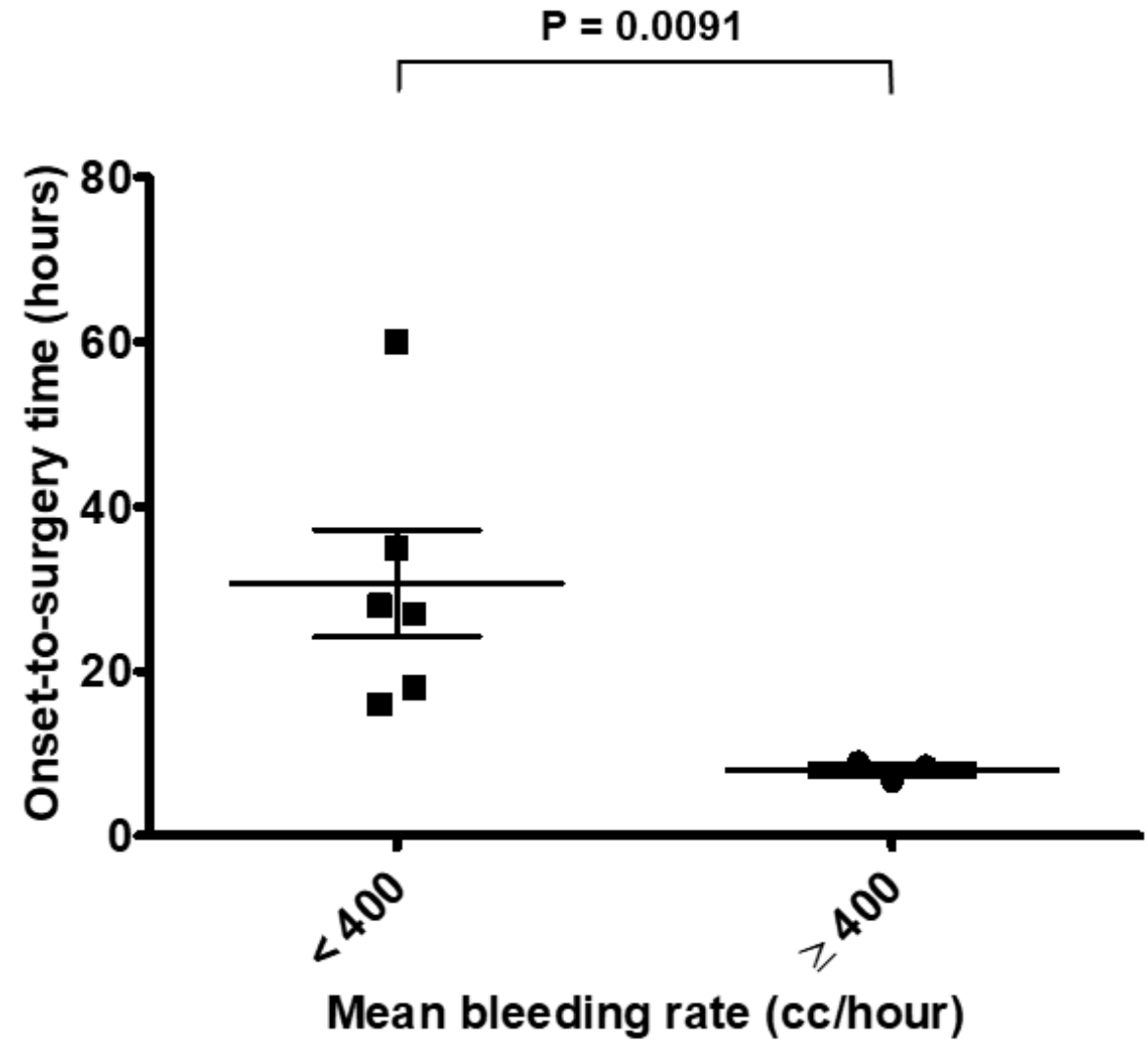

Figure 2

Three patients who had a mean bleeding rate of $\geq 400 \mathrm{cc} /$ hour (Patients 2,7 , and 9) had a significantly shorter onset-to-surgery time (mean, $8.03 \pm 1.27$ hours, range, 6.6-9.0 hours) than the other 6 patients (mean, $30.7 \pm 16.0$ hours, range, $16.0-60.0$ hours; $P=0.0091$ ). 


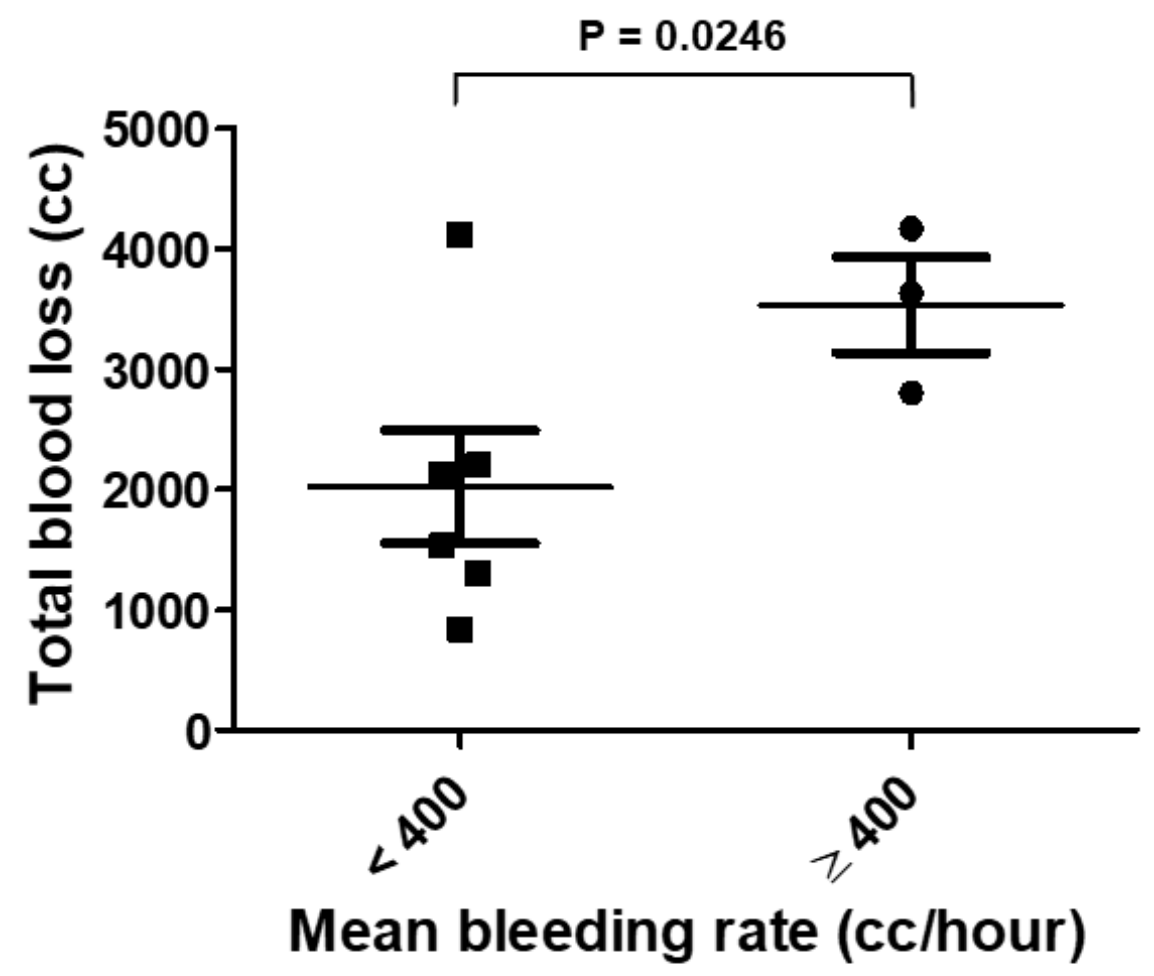

Figure 3

Three patients who had a mean bleeding rate of $\geq 400 \mathrm{cc} /$ hour (Patients 2,7 , and 9) had significantly larger amount of total blood loss (mean, $3533 \pm 690 \mathrm{cc}$, range, $2800-4170 \mathrm{cc}$ ) than the other 6 patients (mean, $2020 \pm 1149 \mathrm{cc}$, range, 840-4120 cc; $\mathrm{P}=0.0246$ ). Online Resource 1: Intraoperative thoracoscopic findings of Patient 2 The preoperative chest radiograph demonstrates a modest mediastinal shift to the right with massive hemothorax on the left chest. A large amount of shed blood (2820cc) was evacuated, and the apical torn

\section{Supplementary Files}

This is a list of supplementary files associated with this preprint. Click to download.

- ONLINERESOURCE101.mpg 